\title{
RESISTÊNCIA À EROSÃO EM RAVINAS, EM LATOSSOLO ARGILOARENOSO(1)
}

\author{
Kalinny Patrícia Vaz Lafayette ${ }^{(2)}$, José Ramon Barros Cantalice $^{(3)} \&$ \\ Roberto Quental Coutinho(4)
}

\begin{abstract}
RESUMO
As ravinas consistem em uma das formas de erosão hídrica com escoamento superficial concentrado em encostas de áreas degradadas e, ainda, sem escoamentos de subsuperfície. Os objetivos deste trabalho foram estudar o comportamento hidráulico do escoamento superficial das ravinas e determinar a erodibilidade $\left(K_{r}\right)$ e a tensão crítica de cisalhamento $\left(\tau_{c}\right)$ na superfície de ravinas e, também, a erodibilidade $\left(K_{r}\right)$ ao longo do perfil de encostas degradadas do litoral do Estado de Pernambuco. O experimento foi realizado em 2005, em um Latossolo Amarelo de textura argilosa pertencente à Formação Barreiras no município do Cabo de Santo Agostinho, PE. As parcelas foram delimitadas por chapas metálicas cravadas no solo no sentido do declive $(1,0 \mathrm{~m}$ de largura por $3,0 \mathrm{~m}$ de comprimento). Os testes consistiram na aplicação de quatro níveis de vazão, determinando-se o volume de descarga líquida e a massa de sedimentos desagregados. As taxas de desagregação de solo foram lineares em relação às tensões de cisalhamento. Na superfície das ravinas, a erodibilidade $\left(K_{r}\right)$ foi de $0,0016 \mathrm{~kg} \mathrm{~N}^{-1} \mathrm{~s}^{-1}$ e a tensão crítica de cisalhamento, de $\tau_{\mathrm{c}}=4,37 \mathrm{~Pa}$. O baixo valor de erodibilidade e o alto de tensão crítica de cisalhamento de $\tau_{\mathrm{c}}$ obtidos na superfície das ravinas possivelmente decorreram da formação de uma crosta superficial originada por ciclos de umedecimento e secagem. A erodibilidade $\left(K_{\mathrm{r}}\right)$ em profundidade variou entre 0,012 e $0,070 \mathrm{~kg} \mathrm{~N}^{-1} \mathrm{~s}^{-1}$, em função do teor de argila. $\mathrm{O}$ regime do escoamento superficial nas ravinas foi turbulento supercrítico e, portanto, semelhante ao do escoamento superficial nos sulcos de erosão, como descrito na literatura.
\end{abstract}

Termos de indexação: erosão hídrica, erodibilidade do solo, crosta superficial, regimes de escoamento.

\footnotetext{
(1) Parte da Tese de Doutorado do primeiro autor, apresentada ao Programa de Pós-Graduação em Engenharia Civil da Universidade Federal de Pernambuco - UFPE. Recebido para publicação em 11 de maio de 2010 e aprovado em 7 de julho de 2011.

(2) Professora do Departamento de Engenharia Civil da Universidade de Pernambuco - UPE. CEP 50720-001 Recife (PE). E-mail: klafayette@poli.br

(3) Professor do Departamento de Engenharia Agronômica, UFRPE, E-mail: cantalic@terra.com.br

(4) Professor do Departamento de Engenharia Civil, UFPE. E-mail: rqc@ufpe.br
} 


\title{
SUMMARY: SOIL EROSION RESISTANCE IN RAVINES IN A SANDY CLAY LOAM OXISOL
}

\begin{abstract}
Ravines represent one of the formations resulting from water erosion, with concentrated surface water flow down hillsides of degraded areas, yet without subsurface water flow. The objective of this study was to evaluate hydraulic flow conditions in ravines as well as to determine soil erosion resistance parameters: soil erodibility $\left(K_{r}\right)$ and critical shear stress $\left(\tau_{c}\right)$ on the ravine surfaces, as well as to determine soil erodibility at several depths of degraded hillsides along the coastline of the state of Pernambuco. The experiment was conducted in 2005, on a sandy clay loam Oxisoil of the "Formação Barreiras" in Cabo de Santo Agostinho. The plots were outlined by metal plates inserted in the soil along the slope $(1.0 \mathrm{~m}$ width $x 3.0$ length). The tests consisted of the application of four flow levels to evaluate the volume of liquid discharge and detached sediment mass. The soil detachment rate was linear to shear stress ( $\tau$ ). Soil erodibility $(\mathrm{Kr})$ was $0.0016 \mathrm{~kg} \mathrm{~N}^{-1} \mathrm{~S}^{-1}$ and the critical shear stress was $4.37 \mathrm{~Pa}$. The low soil erodibility value and high critical shear stress value observed at the surface of the ravines possibly resulted from a soil consolidation process induced by wetting and drying cycles. Soil erodibility $(\mathrm{Kr})$ in depth varied from 0.012 to $0.070 \mathrm{~kg} \mathrm{~N}^{-1} \mathrm{~S}^{-1}$, depending on the clay content. The runoff flow regime in ravines was turbulent supercritical and therefore similar to rill flow, as described in the literature.
\end{abstract}

Index terms: water erosion, soil erodibility, surface sealing, flow regimes.

\section{INTRODUÇÃO}

As ravinas resultam do aumento das dimensões do raio hidráulico e do perímetro molhado dos sulcos de erosão pela ação contínua da ação cisalhante do escoamento. No entanto, nas ravinas só ocorre escoamento superficial, o que as diferencia das voçorocas. Assim, o comportamento hidráulico do escoamento superficial das ravinas é o mesmo dos sulcos de erosão.

A erosão em sulcos constitui a segunda fase evolutiva do processo físico da erosão hídrica do solo, que é marcada pela mudança da forma do escoamento. De difuso, sobre a superfície do solo na fase inicial da erosão em entre sulcos, tal processo se concentra, na segunda fase, em pequenas depressões da superfície do solo chamadas de sulcos de erosão. Quando isso ocorre, a lâmina de escoamento desenvolve maior tensão de cisalhamento pelo aumento da espessura, elevando, portanto, a capacidade do escoamento em desagregar o solo. Em condições naturais, esses pequenos canais ocorrem de maneira espaçada e aleatória, formando uma rede de canais que pode desagregar e transportar grande quantidade de solo (Cantalice et al., 2005).

A determinação do atributo de tensão crítica de cisalhamento e da erodibilidade de diferentes solos que possibilitem a avaliação de sua resistência, juntamente com os modelos de direcionamento e controle de drenagem, deve fazer parte de estudos que visem combater a erosão e proteger o meio ambiente (Oliveira et al., 2009). A determinação desses atributos de resistência em profundidade é muito importante na avaliação da estabilidade estrutural de taludes, embora seja escassa na literatura.
A erodibilidade do solo nos sulcos ou nas ravinas $\left(\mathrm{K}_{\mathrm{r}}\right)$ é representada pela susceptibilidade à desagregação pelo escoamento superficial concentrado. Para Schäfer et al. (2001), um solo pode ser mais ou menos erodível, conforme suas características físicas, químicas e mineralógicas.

O desenvolvimento do modelo WEPP - Water Erosion Prediction Project (Elliot et al., 1989; Flanagan \& Nearing, 1995), baseado nos processos hidráulicos, permitiu a obtenção da erodibilidade em sulcos a partir da relação entre a taxa de desagregação em sulcos e a tensão cisalhante do fluxo, de acordo com a equação (1).

$$
\operatorname{Dr}=K_{\mathrm{r}}\left(\tau-\tau_{c}\right)
$$

em que $\operatorname{Dr}=$ taxa de desagregação em sulcos $\left(\mathrm{kg} \mathrm{m}^{-2} \mathrm{~s}^{-1}\right)$, $\mathrm{K}_{\mathrm{r}}=$ erodibilidade do solo em sulcos $\left(\mathrm{kg} \mathrm{N}^{-1} \mathrm{~s}^{-1}\right.$ ou s m $\left.\mathrm{m}^{-1}\right), \tau=$ tensão cisalhante do fluxo $\left(\mathrm{N} \mathrm{m}^{-2} \mathrm{ou} \mathrm{Pa}\right)$ e $\tau_{\mathrm{c}}=$ tensão crítica de cisalhamento do solo $\left(\mathrm{N} \mathrm{m}^{-2}\right.$ ou $\left.\mathrm{Pa}\right)$.

No Brasil são poucos estudos experimentais no campo e, de maneira geral, têm-se adotado a rotina de cálculo da erosão em sulcos do modelo da WEPP (Braida \& Cassol, 1996; Schäfer et al., 2001; Cantalice et al., 2005) para o estabelecimento das relações entre $\mathrm{K}_{\mathrm{r}}$ e $\tau_{\mathrm{c}}$ e as características físicas e químicas do solo, sendo ainda incipientes as informações obtidas.

Recentemente, Knapen et al. (2007) e Knapen \& Poesen (2010) observaram experimentalmente que a tensão crítica de cisalhamento do solo $\left(\tau_{\mathrm{c}}\right)$ relacionase com os pontos iniciais de formação de sulcos e voçorocas e com a extensão de fluxo concentrado. Uma vez iniciada a formação de sulcos e voçorocas, a forma da seção transversal dessas feições erosivas depende da erodibilidade do solo $\left(\mathrm{K}_{\mathrm{r}}\right)$ ao fluxo concentrado, a 
qual pode ser estimada a partir do conteúdo de água, da densidade do solo, da densidade de raízes e dos resíduos incorporados ao solo, enquanto a tensão crítica de cisalhamento do solo $\left(\tau_{c}\right)$ pode ser relacionada à resistência ao cisalhamento com o solo saturado, pela equação (2):

$$
\tau_{\mathrm{c}}=1,3 \sigma_{\mathrm{s}}+3,6
$$

em que $\sigma_{\mathrm{s}}=$ resistência ao cisalhamento com amostra saturada em $\mathrm{kPa}$ e $\tau_{\mathrm{c}}=$ tensão crítica de cisalhamento do solo em Pa.

Dessa forma, na confirmação da hipótese de similaridade do regime do escoamento superficial entre ravinas e sulcos de erosão, objetivaram-se determinar as condições hidráulicas que se constituem em atributos da modelagem da erosão em ravinas e, ainda, a erodibilidade $\left(K_{r}\right)$ e a tensão crítica de cisalhamento do solo $\left(\tau_{c}\right)$ na superfície dessas ravinas, bem como a erodibilidade do solo $\left(\mathrm{K}_{\mathrm{r}}\right)$ ao longo do seu perfil.

\section{MATERIAL E MÉTODOS}

\section{Obtenção dos dados experimentais}

O experimento foi realizado em 2005, no Parque Metropolitano Armando de Holanda Cavalcanti, localizado no município do Cabo de Santo Agostinho, $\mathrm{PE}$, com latitude (S) $8^{\circ} 17^{\prime} 15^{\prime \prime}$, longitude (WGr) 5 02 ' 00 " e distante aproximadamente $40 \mathrm{~km}$ da cidade do Recife, PE. A região atualmente é de proteção ambiental, compreendendo 270 ha de fauna e flora nativa, e possui, em sua área, o Porto de Suape. No entanto, essa área está inserida numa rota turística praieira, apresentando desmatamento e construção de vias de acesso, o que desencadeou processos de erosão hídrica que têm modificado o meio físico na forma de sulcos e ravinas com grandes proporções.

O solo estudado foi um Latossolo Amarelo distrófico com textura argiloarenosa (Embrapa, 1997), pertencente à Formação Barreiras, que se apresenta sotoposta ao granito, com sequência espessa de arenito com seixos de quartzo no topo. Todo o conjunto rochoso está bastante alterado, facilitando a infiltração da água, resultando em desagregação mecânica, que chega a isolar blocos rochosos. No entanto, a laterização deu-se com grande intensidade nessa área, com a ocorrência de concreções de limonita em superfície.

Os testes experimentais consistiram na aplicação dos seguintes níveis de vazão: $121 ; 172 ; 193$ e $242 \mathrm{~L} \mathrm{~min}^{-1}$, em ravinas que apresentavam superfícies consolidadas. Esses valores foram baseados na média de intensidades de chuvas registradas pela Estação Meteorológica do Curado, próxima ao local do experimento. O delineamento experimental foi inteiramente casualizado com cinco repetições, sendo os resultados submetidos à análise de variância (teste $\mathrm{F}$ a $5 \%$ ), regressões, e teste de Tukey para comparação das médias, por meio do programa estatístico SAS - Statistical Analitical System (SAS, 1998). As ravinas que constituíram as parcelas experimentais foram delimitadas por chapas metálicas de zinco com $30 \mathrm{~cm}$ de altura, $3 \mathrm{~m}$ de comprimento e $1 \mathrm{~m}$ de largura (Figura 1).

A declividade foi obtida pela variação de cota entre os dois pontos mais extremos de cada ravina. A figura 1 apresenta a realização de um ensaio, em que na extremidade superior da parcela foi colocada uma calha de PVC nivelada com a superfície do solo, com a finalidade de dissipar a energia do fluxo no início das ravinas. Um caminhão-pipa com capacidade para $7.000 \mathrm{~L}$ manteve abastecido um reservatório com capacidade para $1.000 \mathrm{~L}$, com o objetivo de manter a carga hidráulica constante. Esse reservatório possuía 10 saídas de água, em que as mangueiras eram conectadas e colocadas nas calhas, localizadas na parte superior das parcelas, por onde a água foi conduzida às ravinas por gravidade. As extremidades inferiores de cada parcela eram providas de calhas condutoras da descarga líquida e do sedimento desagregado, na forma de canos de PVC de $100 \mathrm{~mm}$ de diâmetro.

A velocidade superficial do escoamento foi obtida determinando-se o tempo gasto, em segundos, para que o corante azul de metileno percorresse a distância de 2,0 $\mathrm{m}$ centrais da parcela. Em cada ensaio, a velocidade superficial de escoamento foi determinada concomitantemente com as coletas de descarga líquida e sólida em intervalos de 3 min durante todo o ensaio. Esses valores de velocidade superficial medidos foram multiplicados por um fator de correção

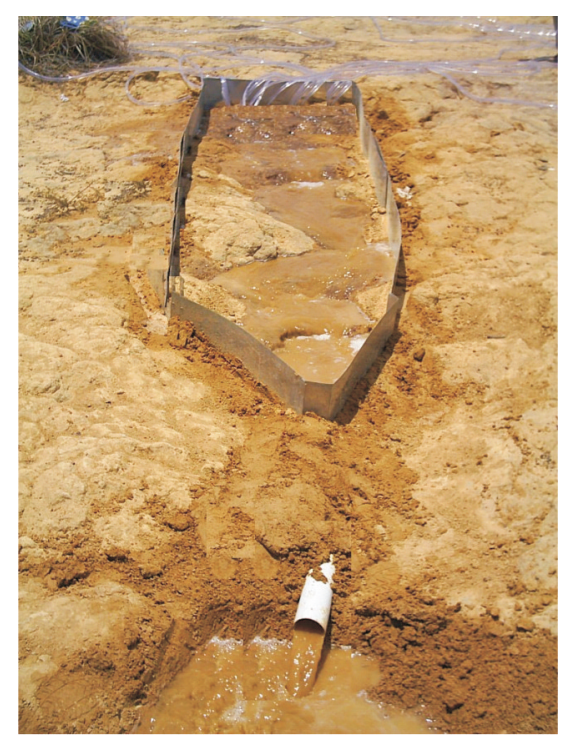

Figura 1. Parcela experimental em ravina com crosta superficial em Latossolo Amarelo distrófico do experimento. 
$\alpha=0,6$ (Cantalice et al., 2005), para obter a velocidade média do escoamento, que é um fator de correção atribuído às variações da velocidade do escoamento superficial com a profundidade do escoamento decorrente do atrito com o solo. Os testes tiveram duração de 30 min, nas vazões aplicadas de 121; 172; 193; e $242 \mathrm{~L} \mathrm{~min}^{-1}$ em três repetições. O volume da descarga líquida com os sedimentos coletados foi colocado em potes plásticos de 1,0 L e transportado para o Laboratório de Solos e Instrumentação da UFPE. Em cada pote plástico após a pesagem, adicionaram-se $5 \mathrm{~mL}$ de alúmen de K $5 \%$ para deposição das partículas de solo. Após 24 h, a água sem partículas foi succionada com uma bomba de vácuo para, em seguida, os potes serem colocados para secar em estufa a $65{ }^{\circ} \mathrm{C}$, para determinação da massa de solo seco, correspondente ao solo desagregado das parcelas.

\section{Determinação dos parâmetros de erosão}

As dimensões das seções transversais do fluxo das ravinas foram aferidas por meio de um perfilômetro, com o objetivo de determinar a área e o perímetro molhado da lâmina de escoamento nas ravinas, segundo Cantalice et al. (2005). O perfilômetro constituiu-se de uma estrutura retangular de acrílico com 0,84 m de comprimento e 0,4 $\mathrm{m}$ de altura, provida de 30 hastes plásticas verticais espaçadas de $2 \mathrm{~cm}$. A partir dessas determinações foram calculados os raios hidráulicos das ravinas de acordo com a equação (3).

$$
R_{h}=\frac{A}{P_{m}}
$$

em que $R_{h}$ = raio hidráulico da seção transversal (m), $\mathrm{A}=$ área da seção transversal $\left(\mathrm{m}^{2}\right)$ e $\mathrm{P}_{\mathrm{m}}=$ perímetro molhado da seção transversal (m).

O número de Reynolds foi determinado pela equação (4).

$$
\mathrm{Re}=\frac{V_{m} \cdot R_{h}}{v}
$$

em que $V_{m}=$ velocidade média de escoamento $\left(\mathrm{m} \mathrm{s}^{-1}\right)$, $\mathrm{R}_{\mathrm{h}}=$ raio hidráulico $(\mathrm{m})$ e $v=$ cinemática da água $\left(\mathrm{m}^{2} \mathrm{~s}^{-1}\right)$.

A temperatura da água nos testes de campo foi de $33{ }^{\circ} \mathrm{C}$. Por conseguinte, a viscosidade cinemática (n) foi tomada como uma constante de $8,02 \times 10^{-7} \mathrm{~m}^{2} \mathrm{~s}^{-1}$.

O número de Froude foi obtido pela equação (5).

$$
F_{r}=\frac{V_{m}}{\sqrt{g R_{h}}}
$$

em que $V_{m}$ = velocidade média do escoamento $\left(\mathrm{m} \mathrm{s}^{-1}\right)$, $\mathrm{g}=$ velocidade de aceleração da gravidade $\left(\mathrm{m} \mathrm{s}^{-2}\right) \mathrm{e}$ $\mathrm{R}_{\mathrm{h}}=$ raio hidráulico $(\mathrm{m})$.

A rugosidade do solo nas ravinas foi determinada através do coeficiente de rugosidade de Manning, obtido a partir da equação (6).

$$
n=\frac{R_{h}^{2 / 3} S^{1 / 2}}{V_{m}}
$$

em que $\mathrm{n}=$ coeficiente de rugosidade de Manning $\left(\mathrm{s} \mathrm{m}^{-1 / 3}\right)$, $R_{\mathrm{h}}=$ raio hidráulico $(\mathrm{m}), \mathrm{S}=$ declive do sulco $\left(\mathrm{m} \mathrm{m}^{-1}\right)$ e $V_{m}$ = velocidade média do escoamento $\left(\mathrm{m} \mathrm{s}^{-1}\right)$.

\section{Quantificação das taxas de desagregação e da erodibilidade do solo nas ravinas}

A partir da massa de solo seco foram determinadas as taxas de desagregação do solo pela equação (7).

$$
D_{r}=\frac{(Q . C)}{L \cdot P_{m}}
$$

em que $\mathrm{D}_{\mathrm{r}}=$ desagregação do solo pelo escoamento nas ravinas $\left(\mathrm{kg} \mathrm{m}^{-2} \mathrm{~s}^{-1}\right), \mathrm{Q}=$ descarga líquida $\left(\mathrm{L} \mathrm{s}^{-1}\right)$, $\mathrm{C}=$ concentração de sólidos no escoamento $\left(\mathrm{kg} \mathrm{L}^{-1}\right)$, $\mathrm{P}_{\mathrm{m}}=$ perímetro molhado $(\mathrm{m})$ e $\mathrm{L}=$ comprimento da ravina $(\mathrm{m})$.

A erodibilidade foi determinada através de análise de regressão do modelo linear entre os valores de tensão cisalhante $(\tau)$ e desagregação do solo $\left(D_{\mathrm{r}}\right)$, conforme a predição de erosão da WEPP (Flanagan \& Nearing, 1995), apresentada na equação (8).

$$
\mathrm{D}_{\mathrm{r}}=\mathrm{K}_{\mathrm{r}}\left(\tau-\tau_{\mathrm{c}}\right)
$$

em que $\mathrm{D}_{\mathrm{r}}=$ taxa de desagregação do solo $\left(\mathrm{kg} \mathrm{m}^{-2} \mathrm{~s}^{-1}\right)$, $\mathrm{K}_{\mathrm{r}}=$ erodibilidade do solo $\left(\mathrm{kg} \mathrm{N}^{-1} \mathrm{~s}^{-1}\right), \tau_{\mathrm{c}}=$ tensão crítica de cisalhamento do solo $(\mathrm{Pa})$ e $\tau=$ tensão cisalhante média do escoamento $(\mathrm{Pa})$. A tensão de cisalhamento média do escoamento foi obtida pela equação (9).

$$
\tau=\gamma R_{h} S
$$

em que $\gamma=$ peso específico da água $\left(\mathrm{N} \mathrm{m}^{-3}\right), \mathrm{R}_{\mathrm{h}}=$ raio hidráulico $(\mathrm{m})$ e $\mathrm{S}=$ declividade do sulco $\left(\mathrm{m} \mathrm{m}^{-1}\right)$. A erodibilidade do solo foi obtida pelo coeficiente "b" da equação que relacionou a taxa de desagregação do solo (Dr) com a tensão cisalhante $(\tau)$. A tensão crítica de cisalhamento $\left(\tau_{c}\right)$ corresponde ao valor do intercepto da tensão de cisalhamento $(\tau)$ quando a taxa de desagregação em sulcos é igual a zero (Laflen \& Thomas, 1987).

$\mathrm{Na}$ determinação da erodibilidade do solo em profundidade, foram coletadas amostras nas profundidades de 1,$7 ; 2,3 ; 4,0 ; 4,5 ; 11,8$; e $12,5 \mathrm{~m}$ para a realização dos ensaios de Inderbitzen no Laboratório de Solos e Instrumentação da UFPE. O valor da erodibilidade do solo na superfície das ravinas foi obtido no experimento de campo.

O ensaio de Inderbitzen consistiu na colocação de amostras inderfomadas sob a ação do escoamento superficial em um equipamento composto por canal de chapa metálica de 0,35 m de largura e 1,2 m de comprimento, dotado de um orifício central com diâmetro de $0,1 \mathrm{~m}$ e altura de 0,05 $\mathrm{m}$, em que foram 
colocadas as amostras indeformadas de solo, já coletadas e confinadas em anéis de PVC biselado. $\mathrm{O}$ fluxo de água adicionado ao canal durante $20 \mathrm{~min}$ foi controlado por registro e agiu sobre a amostra de solo colocada no orifício central e nivelada com a superfície do canal. O sedimento desagregado e transportado passou por um vertedouro central e foi coletado pelo seguinte conjunto de peneiras com malhas de 4,8 , 2,0, 0,42 e 0,074 mm. A tensão de cisalhamento foi determinada pela equação (9), com a altura da lâmina (h) determinada por régua linimétrica acoplada ao canal em substituição ao raio hidráulico.

\section{RESULTADOS E DISCUSSÃO}

As variáveis hidráulicas determinadas nas ravinas estão apresentados no quadro 1 . Os valores de velocidade média do escoamento superficial elevaram-se com as descargas líquidas $\left(\mathrm{L} \mathrm{s}^{-1}\right)$ obtidas e, assim, foram ajustados ao modelo de potência (Figura 1), na forma da equação (10).

$$
\mathrm{V}_{\mathrm{m}}=0,5397 \mathrm{Q}^{0,4057} \mathrm{R}^{2}=0,9165
$$

em que $\mathrm{V}_{\mathrm{m}}$ = velocidade média do escoamento $\left(\mathrm{m} \mathrm{s}^{-1}\right)$ e $\mathrm{Q}=$ descarga líquida dos sulcos $\left(\mathrm{L} \mathrm{s}^{-1}\right)$.

Observam-se, no quadro 1, que foram obtidas as pretendidas elevações de velocidade média do escoamento, área, perímetro molhado, raio hidráulico e tensão de cisalhamento com a aplicação das vazões crescentes. No entanto, para as menores vazões aplicadas não se obteve diferenciação das tensões de cisalhamento. Tal fato ocorreu por conta do efeito dos ciclos de umedecimento e secagem natural que consolidou as camadas subsuperfíciais do solo, formando, assim, as crostas nas ravinas. Ressaltase que a remoção do horizonte A desse Latossolo pela erosão é anterior à formação dessas crostas. Também se observa no quadro 1 que o declive médio das parcelas que receberam a vazão de $193 \mathrm{~L} \mathrm{~min}^{-1}$ foi diferente do declive das demais parcelas e ocasionou diminuição das tensões desse tratamento, o que, no entanto, não prejudicou os resultados de todo o experimento, que foram comprovados pelas análises de regressão. Pode-se deparar com problema dessa natureza na instalação e realização de experimento em campo.

O regime de escoamento nas ravinas foi turbulento rápido em todos os níveis de vazão aplicados, com números de Reynolds (Re) acima de 2.500 e número de Froude $>1$, de acordo com Simons \& Senturk (1992). Regimes turbulentos também foram observados em sulcos de erosão por Schäfer et al. (2001) e Cantalice (2002), embora possam também ocorrer na erosão em sulcos regimes de transição, como verificado por Bezerra (2007), Cantalice et al. (2005) e Bezerra et al. (2010). O regime de escoamento turbulento ocorrido nas ravinas e as demais características hidráulicas (Quadro 1) atestam o comportamento hidráulico do escoamento superficial das ravinas semelhante ao que ocorre nos sulcos de erosão.

Os aumentos das descargas líquidas resultaram em crescentes tensões de cisalhamento do escoamento (Figura 2), as quais deformaram as secções transversais das ravinas, que são demonstradas pela evolução do raio hidráulico e da área das ravinas (Figura 3).

Com base na avaliação das dimensões das seções transversais das ravinas e das taxas médias de desagregação, obtiveram-se a erodibilidade do Latossolo com ravinas $\left(\mathrm{K}_{\mathrm{r}}=0,0016 \mathrm{~kg} \mathrm{~N}^{-1} \mathrm{~s}^{-1}\right)$ e a tensão crítica de cisalhamento $\left(\tau_{\mathrm{c}}=4,37 \mathrm{~Pa}\right)$, por análise de regressão em ajuste linear (figura 4).

A erodibilidade do solo obtida é menor que os valores de 0,$012 ; 0,0024 ; 0, .0077$; e $0,0104 \mathrm{~kg} \mathrm{~N}^{-1} \mathrm{~s}^{-1}$, respectivamente, encontrados por Schäfer et al.

Quadro 1. Características hidráulicas do escoamento superficial nas ravinas sob crostas: velocidade média $\left(\mathrm{V}_{\mathrm{m}}\right)$, área $(\mathrm{A})$, perímetro molhado $\left(\mathrm{P}_{\mathrm{m}}\right)$, raio hidráulico $\left(\mathrm{R}_{\mathrm{h}}\right)$, declive $(\mathrm{D})$, número de Reynolds $(\operatorname{Re})$, Número de Froude (Fr), coeficiente de rugosidade de Manning (n) e tensão de cisalhamento (t). Valores médios de três repetições

\begin{tabular}{|c|c|c|c|c|}
\hline \multirow{2}{*}{ Variável hidráulica } & \multicolumn{4}{|c|}{ Vazão aplicada (L min $\left.{ }^{-1}\right)$} \\
\hline & 121 & 172 & 193 & 240 \\
\hline $\mathrm{V}_{\mathrm{m}}^{(1)}$ & $0,631 \mathrm{c}$ & $0,736 \mathrm{~b}$ & $0,817 \mathrm{a}$ & $0,889 \mathrm{a}$ \\
\hline $\mathrm{A}\left(\mathrm{m}^{2}\right)^{(1)}$ & $0,0023 \mathrm{~d}$ & $0,0029 \mathrm{c}$ & $0,0034 \mathrm{~b}$ & $0,0038 \mathrm{a}$ \\
\hline $\mathrm{P}_{\mathrm{m}}(\mathrm{m})$ & $0,389 \mathrm{~d}$ & $0,433 \mathrm{c}$ & $0,466 \mathrm{~b}$ & $0,491 \mathrm{a}$ \\
\hline $\mathrm{R}_{\mathrm{h}}(\mathrm{m})^{(1)}$ & $5,91 \times 10^{-3} \mathrm{c}$ & $6,69 \times 10^{-3} \mathrm{~b}$ & $7,29 \times 10^{-3} \mathrm{a}$ & $7,73 \times 10^{-3} \mathrm{a}$ \\
\hline $\mathrm{D}\left(\mathrm{m} \mathrm{m}^{-1}\right)^{(1)}$ & 0,13 a & $0,11 \mathrm{a}$ & $0,09 \mathrm{~b}$ & $0,12 \mathrm{a}$ \\
\hline $\operatorname{Re}$ (adim.) & 4567 & 6033 & 7286 & 8419 \\
\hline Fr (adim.) & 2,62 & 2,87 & 3,05 & 3,22 \\
\hline $\mathrm{n}^{(1)}$ & $0,02 \mathrm{a}$ & $0,02 \mathrm{a}$ & $0,01 \mathrm{a}$ & $0,01 \mathrm{a}$ \\
\hline$\tau(\mathrm{Pa})$ & $7,83 \mathrm{~b}$ & $7,08 \mathrm{~b}$ & $6,32 \mathrm{c}$ & $9,31 \mathrm{a}$ \\
\hline
\end{tabular}

(1) Médias seguidas da mesma letra e linha não diferem pelo teste Tukey a $5 \%$. 


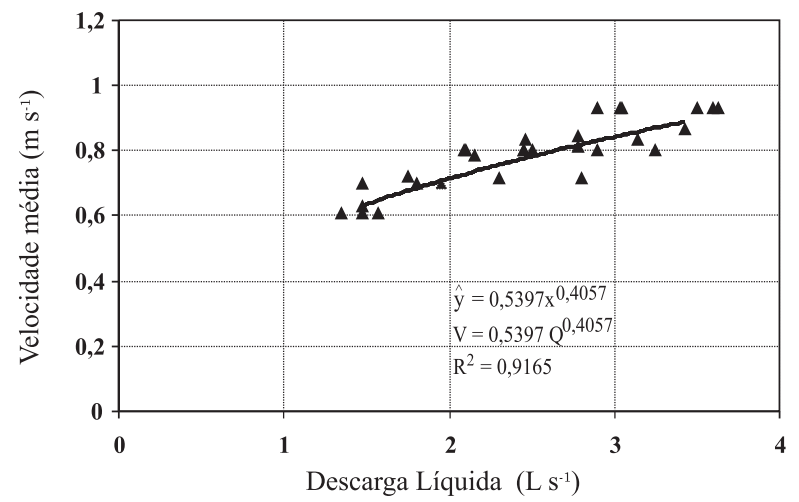

Figura 2. Relação entre a velocidade média do escoamento (V) e as crescentes descargas líquidas (Q).

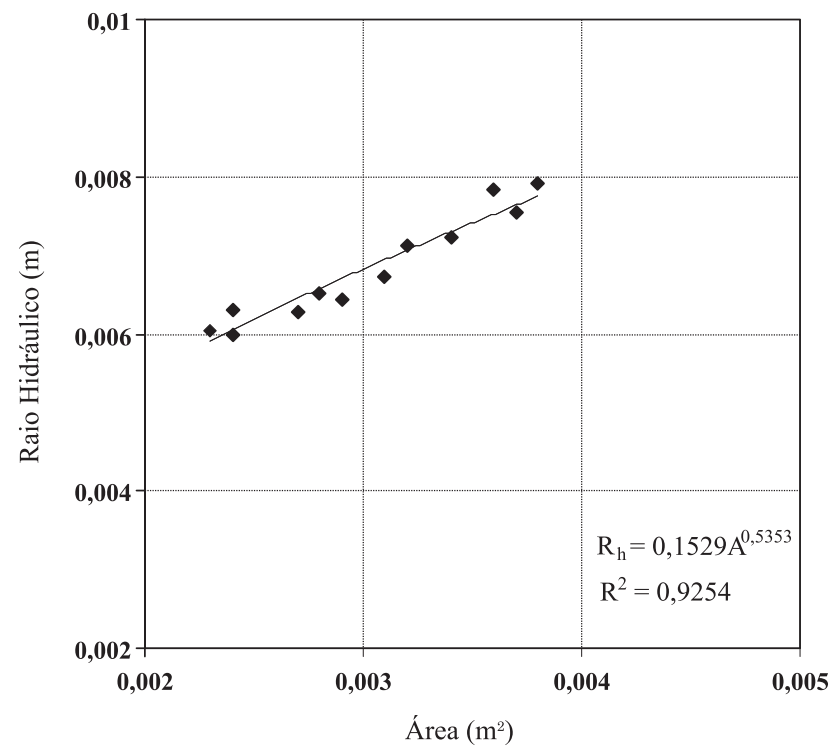

Figura 3. Relação entre a evolução do raio hidráulico $\left(R_{h}\right)$ e a da área (A) das ravinas.

(2001), Cantalice et al. (2005), Giasson \& Cassol (1996) e Braida \& Cassol (1996) em vários Argissolos, o que pode ser justificado em virtude de o Latossolo ser mais desenvolvido e, portanto, mais profundo $(4,5 \mathrm{~m})$, com menor diferenciação de textura, mais bem drenado e com estrutura mais forte pelo intemperismo mais avançado em relação aos Argissolos. Portanto, o Latossolo mostrou-se mais resistente ao escoamento concentrado da erosão hídrica que os Argissolos apresentados na literatura.

A tensão crítica de cisalhamento (4,37 $\mathrm{Pa})$ encontrada nas ravinas também foi superior aos valores críticos e à tensão cisalhante dos Argissolos acima citado, evidenciando-se que o escoamento precisou gastar mais energia para iniciar a desagregação do horizonte exposto do Latossolo com crostas nas ravinas. Esse valor mais elevado da tensão crítica de cisalhamento está relacionado com

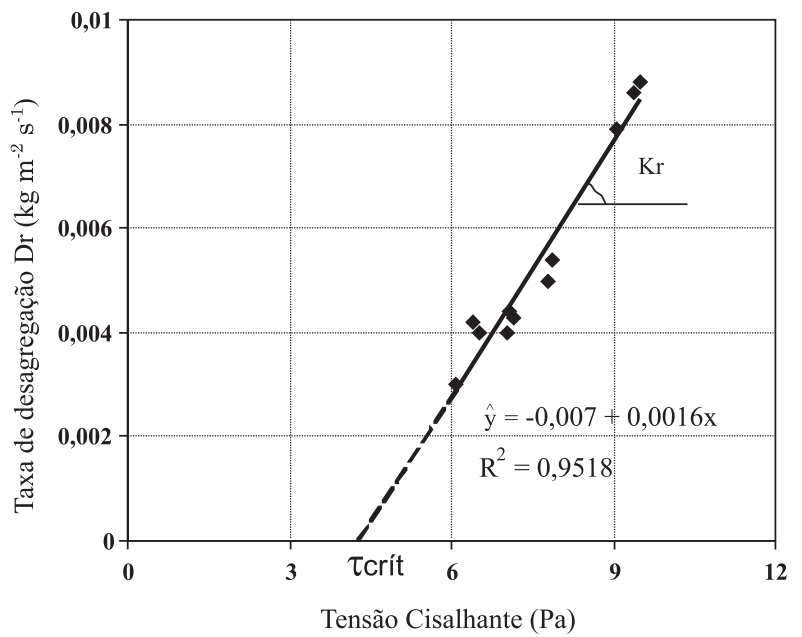

Figura 4. Relação entre a taxa de desagregação (Dr) e a tensão cisalhante $(\tau)$ nas ravinas e a erodibilidade do solo sob ravinas $\left(K_{r}\right)$. (Denise, colocar $\mathrm{kg} \mathrm{Na}$ lateral esquerda da figura)

o fato de que o experimento foi realizado sobre uma crosta superficial, em função dos ciclos de umedecimento e secagem e da exposição dos horizontes subsuperfíciais (B e C), resultantes da decaptação do horizonte superficial A.

\section{Comportamento da erodibilidade do solo em profundidade}

A figura 5 mostra os valores da erodibilidade do solo ao longo do seu perfil, que se ajustaram ao modelo de Hoerl, que é um modelo de regressão não linear das relações de variáveis empíricas e explica 64,4\% da variância da erodibilidade do solo, equação (11).

$K=0,1997\left(0,1096^{\text {prof }}\right)\left(\right.$ prof $\left.^{5,19638}\right) \mathrm{R}^{2}=0,644$

em que $\mathrm{K}$ = erodibilidade do solo em profundidade $\left(\mathrm{kg} \mathrm{N}^{-1} \mathrm{~s}^{-1}\right)$ e prof = profundidade do perfil de solo em (m).

Observa-se (Figura 6) que o Latossolo apresenta menor suscetibilidade à erosão na superfície, que sofreu mais intensamente os efeitos dos ciclos de umedecimento e secagem que geraram as tensões matriciais responsáveis pelo aumento da resistência estrutural da superfície e a formação das crostas. A erodibilidade começa a aumentar em torno da profundidade de $1 \mathrm{~m}$, que marca a mudança de inflexão do primeiro ciclo da curva e atinge a máxima suscetibilidade a 2,3 m e, em seguida, diminui até os $7 \mathrm{~m}$ e pouco se altera até $12 \mathrm{~m}$. A diminuição do valor numérico da erodibilidade a partir de $2,3 \mathrm{~m}$ se deve ao aumento do teor de argila, que implica maior coesão do solo e, portanto, maior resistência à erosão. Observa-se que os valores de erodibilidade em profundidade são 10 vezes superiores aos obtidos na superfície. 


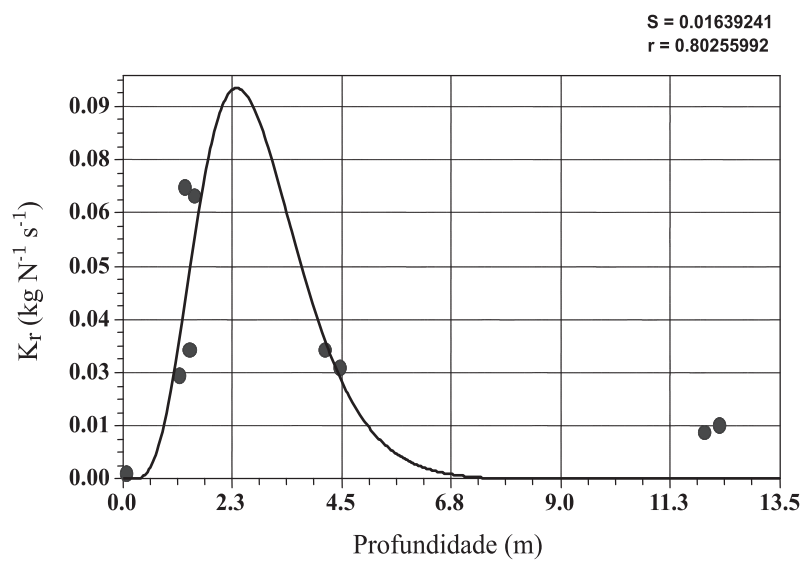

Figura 5. Comportamento da erodibilidade $\left(K_{r}\right)$ do Latossolo argiloarenoso em profundidade.

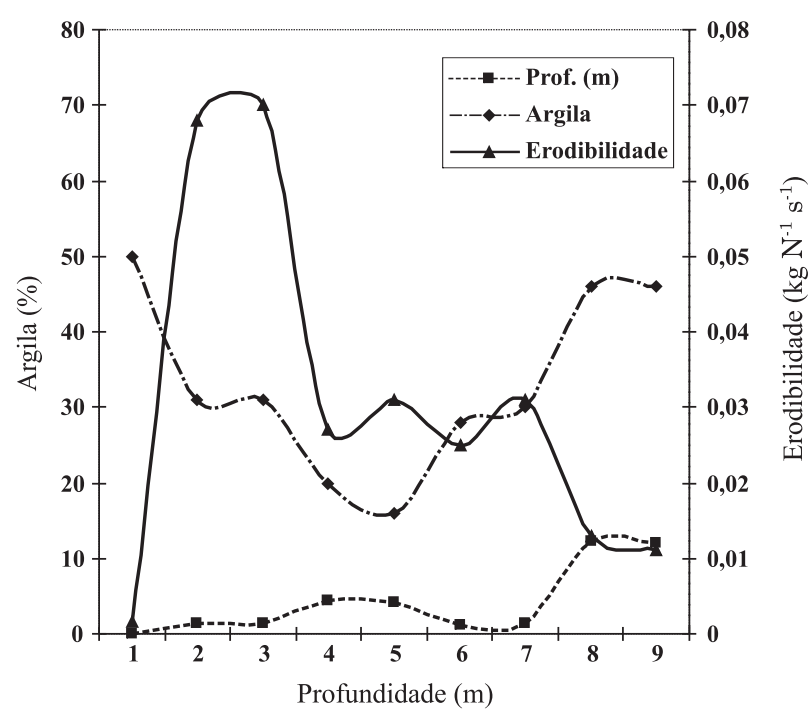

Figura 6. Erodibilidade e teores de argila em profundidade do Latossolo argiloarenoso.

A partir dos 7,0 m de profundidade, os teores de argila voltam a aumentar, e assim a erodibilidade do solo pode estar relacionada com os processos de deposição e da gênese do solo. Portanto, abaixo da faixa de profundidade em que ocorreu o processo de formação das crostas, quem respondeu pela erodibilidade do solo foi o teor de argila.

\section{CONCLUSÕES}

1. O regime de escoamento superficial nas ravinas foi turbulento supercrítico, e as condições hidráulicas do escoamento foram semelhantes às condições de sulcos de erosão, conforme descrito na literatura.

2. Nas ravinas, as taxas de desagregação na superfície do solo responderam de forma linear às tensões de cisalhamento desenvolvidas, sendo o valor da erodibilidade nessas tensões de $0,0016 \mathrm{~kg} \mathrm{~N}^{-1} \mathrm{~s}^{-1} \mathrm{e}$ o da tensão crítica de cisalhamento, de 4,27 Pa.

3. Abaixo da faixa de profundidade em que ocorreu o processo de formação das crostas do Latossolo estudado, quem respondeu pelas variações de erodibilidade do solo foi o teor de argila, com valores entre 0,012 e $0,07 \mathrm{~kg} \mathrm{~N}^{-1} \mathrm{~s}^{-1}$.

4. Os valores de erodibilidade em profundidade foram 10 vezes superiores aos obtidos na superfície, por conta dos ciclos de umedecimento e secagem que consolidaram a superfície, elevando, assim, a resistência do solo à erosão.

\section{LITERATURA CITADA}

BRAIDA, J.A. \& CASSOL, E.A. Erodibilidade em sulcos e em entre sulcos de um Podzólico Vermelho-Escuro franco arenoso. R. Bras. Ci. Solo, 20:127-134, 1996.

BEZERRA, S.A. Transporte de sedimentos em sulcos de erosão experimentais no semi-árido de Pernambuco. Recife, Universidade Federal de Pernambuco, 2007. (Tese de Doutorado)

BEZERRA, S.A.; CANTALICE, J.R.B.; CUNHA FILHO, M. \& SOUZA, W.L.S. Características hidráulicas da erosão em sulcos em um Cambissolo do semi-árido do Brasil. R. Bras. Ci. Solo, 34:1225-1332, 2010.

CANTALICE, J.R.B.; CASSOL, E.A.; REICHERT, J.M. \& BORGES, A.L.O. Hidráulica do escoamento e transporte de sedimentos em sulcos em solo franco argilo arenoso. R. Bras. Ci. Solo, 29:597-607, 2005.

CANTALICE, J.R.B. Alterações do escoamento e das taxas de desagregação na erosão em sulcos em condições de solo recém preparado e consolidado. In: REUNIÃO BRASILEIRA DE MANEJO E CONSERVAÇÃO DO SOLO E DA ÁGUA, 14., Cuiabá, 2002; REUNIÃO BRASILEIRA DE MANEJO E CONSERVAÇÃO DO SOLO E DA ÁGUA, 2002, Viçosa, MG. Anais... Viçosa, MG, Sociedade Brasileira de Ciência do Solo, 2002.

ELLIOT, W.J.; LIEBNOW, A.M.; LAFLEN, J.M. \& KOHL, K.D. A compendium of soil erodibility data from WEPP cropland soil field erodibility experiments 1987 \& 88 . West Lafayette, The Ohio State University and USDA-ARS, 1989. (NSERL - National Soil Erosion Research Laboratory Report, 3)

EMPRESA BRASILEIRA DE PESQUISA AGROPECUÁRIA EMBRAPA. Centro Nacional de Pesquisa de Solos. Manual de métodos de análise de solo. 2.ed. Rio de Janeiro, 1997. $212 \mathrm{p}$.

FLANAGAN, D.C. \& NEARING, M.A. United States Department of Agriculture-USDA: Water Erosion Prediction Project. West Lafayette, National Soil Erosion Research Laboratory - NSERL, 1995. (Technical Documentation, 10)

GIASSON, E. \& CASSOL, E.A. Relações de erosão em sulcos com vazões aplicadas e doses de resíduo de trigo incorporados a Plintossolo franco argilo arenoso. R. Bras. Ci. Solo, 20:117-125, 1996. 
KNAPEN, A.; POESEN, J.; GOVERS, G.; GYSSELS, G. \& NACHTERGAELE, J. Resistance of soils to concentrated flow erosion: A review. Earth Sci. Rev., 80:75-109, 2007.

KNAPEN, A. \& POESEN, J. Soil erosion resistance effects on rill and gully initiation points and dimensions. Earth Surface Process Landforms, 35, 217-228, 2010.

LAFLEN, J.M. \& THOMAS, A.W. Cropland experiments for the WEPP project. In: INTERNATIONAL WINTER MEETING OF THE AMERICAN SOCIETY OF AGRICULTURAL ENGINEERS, 1987, Illinois. [Papers]. St. Joseph, American Society of Agricultural Engineers, 1987. 14p. (Paper n. 87-2544).

OLIVEIRA, J.F.; GRIEBELER, N.P.; CORRECHEL, V. \& SILVA, V.C. Erodibilidade e tensão crítica de cisalhamento em solos de estradas não pavimentadas. R. Bras. Eng. Agríc. Amb., 13:955-960, 2009.
SAS Institute, Inc. The SAS System for windows: Release ver. 6.8. Cary, 1998. CD ROM.

SCHÄFER, M.J.; REICHERT, J.M.; CASSOL, E.A.; ELTZ, F.L.F. \& REINERT, D.J. Erosão em sulcos em diferentes preparos e estados de consolidação do solo. R. Bras. Ci. Solo, 25:419-430, 2001.

SIMONS, D.B. \& SENTURK, F. Sediment transport technology: Water and sediment dynamics. Littleton, Water Resources Publications, 1992. 